\title{
Time for Revision of the Post Graduate Prosthodontic Curriculum?
}

\author{
Shilpa Shetty
}

Published online: 31 July 2014

(C) Indian Prosthodontic Society 2014

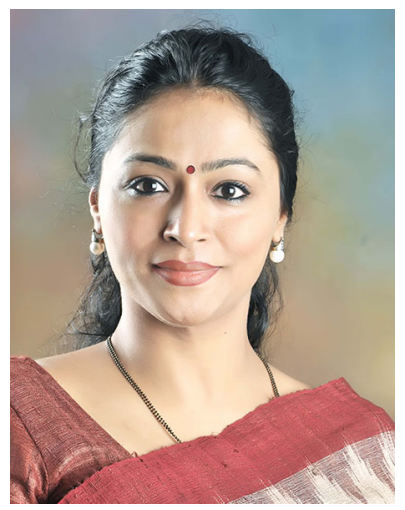

One of the most exhaustive branches of dentistry is prosthodontics. Prosthodontics comprises of fixed denture prosthodontics, Removable prosthodontics, maxillofacial prosthetics and Implant prosthodontics. There is a compelling need to change the existing postgraduate curriculum and the examination system followed in India.

No doubt the prevalence of completely edentulous situation among the general population is greater but there is a growing trend of partially edentulous situations as well due to the raised levels of awareness on oral health [1,2].

And it is time we incorporate the management of partially edentulous situations in our curriculum and teach our students who are going to be the future generation of prosthodontists the management of these situations while retaining our traditional concepts and at the same time introducing the advances in technology and research into the education system.

S. Shetty $(\bowtie)$

Banglore, India

e-mail: editor.ipsjournal@gmail.com

\section{References}

1. Chhabra A, Chhabra N, Kabi D, Jain A (2013) Understanding dental status and treatment need of geriatric patients: oral health trends in an Indian population. Oral health dent comp 12(4):213-216

2. Reddy NS, Reddy NA, Narendra R, Reddy SD (2012) Epidemiological survey on edentulousness. J contemp dent pract 13(4): $562-570$

3. Udey VA (2014) Current status and expected future direction of the prosthodontic speciality in India: JPS Global Workshop Kyoto 2012. J prosth res 58:137-190 